\title{
Testosterone, LH and FSH episodic secretory patterns in GnRH-immunized bulls
}

\author{
M. Finnerty ${ }^{1,2}$, W. J. Enright ${ }^{1}$ and J. F. Roche ${ }^{2 *}$ \\ ${ }^{1}$ Teagasc, Grange Research Centre, Dunsany, County Meath, Ireland; and \\ ${ }^{2}$ Faculty of Veterinary Medicine, University College Dublin, Ireland
}

\begin{abstract}
The objective was to determine: (i) the secretory patterns of LH, FSH and testosterone in bulls, and the temporal relationships between the pulses of these hormones; and (ii) the effect of GnRH immunization on these parameters. Friesian bulls $(n=72)$ were given a primary immunization on day 0 (10-week-old) and a booster immunization on either day $28(n=36)$ or day $56(n=36)$ against either a GnRH-human serum albumin (HSA) conjugate $(n=48)$ or HSA ( $n=24$; control). On the basis of GnRH antibody titres at a plasma dilution of $1: 160,1$ week after booster immunization, $12 \mathrm{GnRH}$-immunized and six control bulls from each booster-immunized group were selected and allocated to one of three groups: control bulls and bulls with medium and high antibody titres $(0.3,32$ and $51 \%$ binding, respectively; pooled SED $4.3 \%)$. Blood samples were taken from these animals $(n=36)$ every $15 \mathrm{~min}$ for $8 \mathrm{~h}$ on three occasions: (i) 2 weeks after booster immunization when bulls were $4-5$ months of age (prepubertal); (ii) at 7 months of age (peripubertal); and (iii) at 11 months of age (post-pubertal). Data were analysed by PULSAR ${ }^{\circledR}$, ANOVA and chi-squared test. The mean antibody titre of the high antibody titre group was greater $(P<0.05)$ than that of the medium antibody titre group in prepubertal bulls only, but the mean antibody titres of both antibody titre groups were greater $(P<0.05)$ than that of the control bulls at all times. The frequency and amplitude of LH and FSH pulses in the control bulls were greater $(P<0.05)$ during prepuberty than after puberty. The frequency, amplitude and duration of LH pulses were greater $(P<0.05)$ in control bulls than those in medium and high antibody titre bulls at prepuberty. The mean and basal concentrations of FSH and the amplitude and duration of FSH pulses were greater $(P<0.05)$ in the control bulls than in the high antibody titre bulls at prepuberty. The frequency of testosterone pulses was greater $(P<0.05)$ in the control bulls than in the medium and high antibody titre bulls at peripuberty. The mean and basal concentrations and pulse amplitude of testosterone were greater $(P<0.05)$ in high antibody titre bulls than in control bulls after puberty. There was a close temporal relationship between $\mathrm{LH}$ and FSH $(62.5 \%$ of $\mathrm{LH}$ pulses were followed by FSH pulses within $75 \mathrm{~min}$ ) at prepuberty in the control bulls but there was no relationship after puberty. The opposite trend occurred in the high antibody titre bulls, that is, there was no relationship between LH and FSH at prepuberty but there was a close temporal relationship after puberty. The temporal relationship between LH and testosterone was closest at peripuberty $(86.7 \%)$ in the control bulls, but increased in the high antibody titre bulls from $0 \%$ at prepuberty to $57.1 \%$ after puberty. In summary, there was an age-related decrease in LH and FSH pulse frequency and amplitude and also in the temporal relationships between these hormones in control bulls. Prepubertal GnRH immunization had a suppressing effect on the pulsatile release of LH, FSH and testosterone before but not after puberty. The presence of high amplitude testosterone pulses in the GnRH-immunized bulls after puberty indicates that the long-term tonic release of LH may be sufficient to initiate a late pubertal-type increase in testosterone concentrations.
\end{abstract}




\section{Introduction}

The onset of pubertal development occurs in the bull between 4 and 5 month of age and is marked by increases in testosterone concentrations and testes size and the initiation of spermatogenesis (MacMillan and Hafs, 1968; McCarthy et al., 1979a,b; Schanbacher, 1979). The end of this period of development is reached when bulls attain the ability to produce viable spermatozoa and this occurs in most breeds of bull by 11 months of age (Lunstra et al., 1978). In this study the period of pubertal development, that is, between 5 and 10 months of age, is called the peripubertal period.

Changes in the episodic secretion of $\mathrm{GnRH}$ regulate the secretion of the gonadotrophins $\mathrm{LH}$ and $\mathrm{FSH}$ in the prepubertal bull and thus, ultimately regulate testicular function (Courot, 1978; Rodriguez and Wise, 1989). Specifically, Rodriguez and Wise (1989) demonstrated that an increase in GnRH pulsatile release from the hypothalamus occurs between 6 and 10 weeks of age in the bull and is followed at $8-10$ weeks of age by the pulsatile release of $\mathrm{LH}$. This release of $\mathrm{LH}$ causes increased serum testosterone concentrations which peak at approximately 10 months of age (Rawlings et al., 1978; McCarthy et al., 1979a). It is well documented that the amplitude and frequency of LH pulses change with the reproductive state of the male, the secretion of both $\mathrm{LH}$ and testosterone is episodic (Lincoln, 1976; Schams et al., 1978; Ellis and Desjardins, 1982), and there is a temporal relationship between these two hormones in the bull (Katongole et al., 1971; Karg et al., 1976; McCarthy et al., 1979a).

Although the gonadotrophin hormones play a crucial role in stimulating sexual maturation in the male, the existence of any relationship between the pattern of release of $\mathrm{LH}$ and FSH has not been verified. In addition, the pattern of release of FSH and the endocrine mechanisms regulating the secretion of FSH in the bull are poorly understood. Specifically, there is conflicting evidence with respect to changes in mean concentrations of FSH during reproductive development in the male. Mean serum FSH concentrations were reported to increase before the onset of spermatogenesis in lambs and bulls, that is, between 1 and 4 months of age (Lee et al., 1976; Amann and Schanbacher, 1983). In addition, Evans et al. (1993) reported a peak in mean FSH concentrations in the bull at 20 weeks of age. However, McCarthy et al. (1979b) and D'Occhio et al. (1986) reported no change in mean serum FSH concentrations in bulls from 1 to 10 and from 4 to 9 months of age, respectively.

Several studies report conflicting findings with respect to the temporal relationship between the pulsatile or episodic patterns of secretion of $\mathrm{LH}$ and FSH and that of LH and testosterone. Karg et al. (1976) found no significant correlation between concentrations of FSH and LH from 1 to 10 months of age. Malak and Thibier $(1985 a, b)$ reported that FSH was not secreted in an episodic pattern on the basis of frequent blood samples taken from post-pubertal bulls. Furthermore, Evans et al. (1993), using frequent blood samples taken from bulls of 1-8 months of age, did not report any temporal relationship between $\mathrm{LH}$ and $\mathrm{FSH}$, or $\mathrm{LH}$ and testosterone even though a temporal relationship between testosterone and oestradiol was reported. In contrast,
Schams et al. (1978) demonstrated that FSH was secreted in an episodic pattern and that there was a clear relationship between the spontaneous episodic release of LH, FSH and testosterone in the peripheral plasma of 11-month-old Friesian bulls. In addition, Lincoln (1978) reported that episodic peaks of plasma LH were associated with increases in both FSH and testosterone in the sexually active ram; and Rawlings et al. (1978) reported a temporal relationship between the episodic release of $\mathrm{LH}$ and testosterone at the end of the pubertal period in bulls. This lack of consistency in the literature is due to a large variation in the frequency of blood sampling, the age of the animals at the time of sampling, the reliability of the FSH assays used, and the definition and methods of detecting pulses.

Previous studies have shown that passive (Lincoln and Fraser, 1979) and active (Schanbacher, 1982; Brown et al., 1994) immunization against $\mathrm{GnRH}$ in the prepubertal ram suppress the pulsatile release of $\mathrm{LH}$ and the episodic secretion of testosterone, and cause a marked reduction in mean FSH concentrations after booster immunization. However, most GnRH immunization studies to date have looked at the effect on mean concentrations of $\mathrm{LH}$, testosterone (Lincoln and Fraser, 1979; Schanbacher, 1982) and FSH (Brown et al., 1994). The temporal relationships between the episodic secretory patterns of $\mathrm{LH}$, testosterone and FSH during the first year of life in bulls and the effect of $\mathrm{GnRH}$ immunization on these three hormones have not been examined.

This study used bulls at 4-5 months (prepuberty), 7 months (peripuberty) and 11 months of age (post-puberty). The objectives were: (i) to determine the temporal relationship between the episodic secretory patterns of $\mathrm{LH}$, FSH and testosterone at different times during development, and the changes in these temporal relationships with age; and (ii) to determine the effect of prepubertal GnRH immunization on the subsequent secretory patterns of $\mathrm{LH}$, FSH and testosterone, and the effect of medium and high GnRH antibody titres in prepuberty on the subsequent secretory patterns of LH and testosterone.

\section{Materials and Methods}

\section{Animals and treatment groups}

Seventy-two 8- to 10-week-old autumn-born Friesian bull calves were blocked and assigned to 12 treatments as described by Finnerty et al. (1994). Briefly, the main effects were as follows: (i) dose of a human serum albumin (HSA)-Cys-Gly-GnRH conjugate (GnRH; 0, 0.1 or $1.0 \mathrm{mg}$ ); (ii) adjuvant type (diethylaminoethyl-dextran or nonulcerative Freund's adjuvant); and (iii) interval between primary immunization (day 0) and booster immunization (day 28 or 56 ). The bulls in the $0 \mathrm{mg}$ treatment group were immunized against HSA $(n=24)$. On the basis of antibody titres (expressed at a 1:160 plasma dilution) 1 week after the respective booster immunization, 36 bulls were selected across the 12 original treatments outlined above, and allocated to one of three antibody titre treatment groups. The three groups were as follows: (i) control (HSA-immunized; 
$n=12) ; 0.3 \pm 0.1 \%$ (mean \pm SEM) ${ }^{125}$ I-labelled GnRH binding; (ii) medium (GnRH-immunized; $n=12$ ); $32 \pm 2 \%{ }^{125} \mathrm{I}$-labelled GnRH binding; (iii) high (GnRH-immunized; $n=12$ ); $51 \pm$ $2 \%{ }^{125} \mathrm{I}$-labelled GnRH binding. Fourteen days after the booster immunization at day 28 , blood samples were collected from bulls that had received this booster, that is, samples were taken from six bulls from each of the control, medium and high antibody titre groups (animals were approximately 4 months of age). Similarly, 14 days after the booster immunization at day 56 , blood samples were taken from bulls that had received this booster (animals were approximately 5 months of age). Initial statistical analyses on the data from these two blood sampling periods indicated that the timing of the booster immunization had no effect on any of the variables measured. Therefore, these two blood sampling periods were combined and are referred to as BL4/5 (blood sampled at 4-5 months of age). Subsequently, intensive blood sampling was performed on all bulls at approximately 7 (BL7) and 11 months of age (BL11). For collection of blood samples bulls were tied in individual stalls 3 days before sampling, given ad libitum access to grass silage and offered $2 \mathrm{~kg}$ of barley per animal day ${ }^{-1}$. An indwelling catheter was inserted into the jugular vein and each animal was returned to their individual stalls by $10: 30 \mathrm{~h}$ the day before sampling commenced. Blood samples were initially collected at 08:00, 08:30 and 08:45 $\mathrm{h}$ to accustom the bulls to the procedure and thereafter every $15 \mathrm{~min}$ from 09:00 to $17: 00 \mathrm{~h}$. Plasma was separated by centrifugation of the samples at $1600 \mathrm{~g}$ for $25 \mathrm{~min}$ and was stored at $-20^{\circ} \mathrm{C}$ until assayed for $\mathrm{LH}, \mathrm{FSH}$ and testosterone. GnRH antibody titres were determined in a single sample taken 7 days after booster immunization and in the sample collected at 08:00 $\mathrm{h}$ on each blood sampling day.

\section{Hormone assays}

Luteinizing hormone. Plasma LH concentrations were determined by radioimmunoassay as described by Finnerty et al. (1994). The sensitivity of the LH assay was $0.5 \mathrm{ng} \mathrm{ml}^{-1}$. The LH intra-assay coefficients of variation $(\mathrm{CV})(n=10)$ were 6.0 and $12.0 \%$ for plasma samples containing 1.0 and 5.5 ng $\mathrm{LH} \mathrm{ml}^{-1}$, respectively. The interassay CV $(n=10)$ for the same two samples were 10 and $13 \%$, respectively. The crossreactivity of bovine FSH (NIH B1 bFSH) with the NIDDK-anti-oLH antibody was $6.3 \%$.

Follicle stimulating hormone. Plasma FSH concentrations were determined using a heterologous radioimmunoassay as described by Crowe et al. (1997) using the NIDDK-antioFSH antibody and bovine FSH standard preparation (NIH B1 bFSH). FSH assays were run on blood samples from six randomly selected bulls from the control and high antibody titre groups only. The sensitivity of the FSH assay was $2.0 \mathrm{ng} \mathrm{ml}^{-1}$. Intra-assay $\mathrm{CV}$ for the $\mathrm{FSH}$ assay for serum samples containing $13.9,27.0$ and $84.0 \mathrm{ng} \mathrm{FSH} \mathrm{ml}^{-1}$ were 6.0, 7.0 and $10 \%$, respectively. The interassay CV $(n=6)$ for the same serum samples were $9.5,10.7$ and $12 \%$, respectively. The crossreactivity of bovine LH (NIH B9 bLH) with the NIDDK-anti-oFSH antibody was $0.7 \%$.

Testosterone. Plasma testosterone concentrations were determined by a direct radioimmunoassay procedure as described by Ronayne et al. (1993) and Finnerty et al. (1994). Testosterone assays were run on blood samples from six randomly selected bulls from each of the three antibody titre groups. The sensitivity of the assay was $0.05 \mathrm{ng} \mathrm{ml}^{-1}$. The testosterone intra-assay CV $(n=10)$ were 4.8 and $11.0 \%$ for plasma samples containing 1.5 and $10.0 \mathrm{ng}$ testosterone $\mathrm{ml}^{-1}$, respectively. The interassay $\mathrm{CV}(n=6)$ for the same samples were 10 and $15 \%$, respectively.

GnRH antibody titres. Plasma GnRH antibody titres were determined by radioimmunoassay as described by Finnerty et al. (1994). Animals were selected based on antibody titre data presented as the percentage of I $^{125}$-labelled $\mathrm{GnRH}$ bound at a 1:160 dilution. Antibody titres were also determined at higher dilutions (1:160-1:40000) on each of the sampling days and data are presented at both the original 1:160 dilution and at a 1:2560 dilution (this was the highest dilution at which all animals on day 90 after primary immunization had binding greater than the non-specific binding of the assay). Intra- $(n=10)$ and interassay $C V$ $(n=10)$ for a standard bovine antiserum plasma were 3.5 and $6.8 \%$ binding at the $1: 160$ dilution and 4.2 and $7.5 \%$ binding at the 1:2560 dilution, respectively. The mean non-specific binding (for ten replicates) was $1.6 \%$ at $1: 160$ and $1.4 \%$ at 1:2560; therefore, the total binding values were not adjusted.

\section{Pulse analyses}

Profile data of $\mathrm{LH}, \mathrm{FSH}$ and testosterone concentrations were analysed using the PULSAR ${ }^{\otimes}$ pulse identification routine (Merriam and Wachter, 1982). Pulse analyses were carried out on 33 data points per animal per bleed day. The smoothing time was set at $480 \mathrm{~min}$. The calculated peak selection cut-off values, G1-G5, were 4.5, 2.2, 2.0, 1.3 and 1.0 for $\mathrm{LH} ; 4.5,1.25,0.4,0.3$ and 0.25 for FSH; and 3.25, 2.10, 1.10, 0.90 and 0.7 for testosterone. The PULSAR ${ }^{\circledR}$ program uses an interpolating function to model assay SD as a function of dose and calculates SD as follows: $(y)=\left(A y^{2}+B y+C\right) / 100$. The quadratic, linear and constant coefficients calculated for the assays were $0.287,0.02$ and 16.43 for $\mathrm{LH} ; 0.043,2.1$ and 32.69 for FSH; and $0.76,11.55$ and 6.8 for testosterone. The peak splitting cut-off value used for testosterone was 0.7 . Remaining inputs were the default values suggested by Merriam and Wachter (1982) and the base concentrations referred to in this paper are the smoothed series mean concentrations calculated by the PULSAR ${ }^{\infty}$ program.

\section{Statistical analyses}

The mean number of pulses per $8 \mathrm{~h}$ bleed (frequency) for each antibody titre group was calculated across the total number of animals in each group. However, the mean amplitude and duration of pulses were calculated only for those animals in which pulses were detected. The mean and basal concentrations of each hormone and the mean frequency, amplitude and duration of the pulses or episodic secretions of each hormone were analysed by ANOVA for a split-plot design (treatment in the main plot and bleed day in 
the sub-plot). Specific differences between means were determined using Fishers (Gill, 1978) least significant difference test (two-sided). As mentioned previously, FSH concentrations were determined in six randomly selected bulls from each of the control and high antibody titre groups only. Therefore, pulses or episodic secretions of all three hormones were plotted for each of these animals to establish whether there was a relationship between the temporal patterns of release of $\mathrm{LH}, \mathrm{FSH}$ and testosterone. The number of LH pulses that occurred during the first $6.5 \mathrm{~h}$ of each blood sampling period that were followed within 75 min by FSH and testosterone episodic secretions was noted. The proportion of LH pulses followed by FSH and testosterone episodic secretions was calculated and the Fisher exact probability test for two independent samples (Siegel, 1956) was used to determine differences between antibody titre groups within bleed days; chi-squared analyses were used to determine differences within antibody titre groups over time. The antibody titre data for the medium and high antibody titre groups on each bleed day were analysed by ANOVA.

\section{Results}

\section{Antibody titres}

Mean GnRH antibody titres were higher $(P<0.05)$ in both the medium and high antibody titre bulls than in the control bulls at both plasma dilutions, at all sample times. The high antibody titre bulls had a higher $(P<0.05)$ mean antibody titre (at both dilutions) than the medium antibody titre bulls during BL4/5 only (Table 1). There was no effect $(P>0.10)$ of time on antibody titre.

Table 1. The overall mean GnRH antibody titre (percentage binding) and the antibody titre from one plasma sample taken at the start of each of three intensive blood sampling schedules conducted at 4-5 (BL4/5), 7 (BL7) and 11 (BL11) months of age in bulls immunized at $8-10$ weeks of age against a GnRH-human serum albumin (HSA) conjugate

\begin{tabular}{llcrrr}
\hline \multirow{2}{*}{$\begin{array}{l}\text { Plasma } \\
\text { dilution }\end{array}$} & $\begin{array}{c}\text { Antibody } \\
\text { titre group }\end{array}$ & $\begin{array}{c}\text { Overall } \\
\text { antibody titre }\end{array}$ & BL4/5 & BL7 & BL11 \\
\cline { 4 - 6 } $1: 160$ & Medium & $38.0^{\text {a }}$ & $35.7^{\text {a }}$ & 39.0 & 39.3 \\
& High & $51.1^{\mathrm{b}}$ & $55.2^{\mathrm{b}}$ & 48.5 & 49.6 \\
& SED $^{*}$ & 4.6 & 4.5 & 5.8 & 7.2 \\
$1: 2560$ & & & & & \\
& Medium & 15.7 & $14.1^{\text {a }}$ & 18.8 & 12.7 \\
& High & 23.7 & $25.9^{\mathrm{b}}$ & 27.6 & 17.5 \\
& SED $^{*}$ & 4.2 & 4.1 & 5.2 & 6.6 \\
& & & & &
\end{tabular}

Antibody titres are given at two plasma dilutions (1:160 and 1:2560) for bulls immunized at 8-10 weeks of age against a GnRH-HSA conjugate (Finnerty et al., 1994), selected at 13-19 weeks of age on the basis of GnRH antibody titres and allocated to one of two antibody titre groups: medium $(n=12 ; 32 \pm 2 \%$ at 1:160 plasma dilution) and high ( $n=12 ; 51 \pm 2 \%$ binding).

"Means within a plasma dilution and within column with different superscripts are significantly different $(P<0.05$; two-sided test).

*SED between two treatment means.

\section{Mean and basal hormone concentrations}

Mean LH concentrations were higher in the control bulls $(P<0.05)$ during BL4/5 (Table 2) than during BL7 or BL11. Mean and basal concentrations of LH were higher $(P<0.05)$ in both the medium and high antibody titre groups during BL11 than during BL4/5 or BL7 (Table 2). Mean and basal concentrations of $\mathrm{LH}$ were greater $(P<0.05)$ in the control bulls compared with the medium and high antibody titre groups during BL4/5 only (Table 2). Mean and basal concentrations of FSH were higher $(P<0.05)$ in the control bulls during BL4/5 than during BL7 and BL11, and were higher $(P<0.05)$ in the control bulls compared with the high antibody titre bulls during BL4/5 (Table 3). There were no differences $(P>0.05)$ in mean and basal LH and FSH concentrations between antibody titre groups during BL7 and BL11 (Tables 2 and 3).

Mean and basal testosterone concentrations did not change with age in the control bulls (Table 4). The control bulls had a higher $(P<0.05)$ mean testosterone concentration than the high antibody titre bulls during BL7. However, by BL11, the high antibody titre bulls had higher $(P<0.05)$ mean and basal concentrations of testosterone than the controls (Table 4). The high antibody titre bulls had higher $(P<0.05)$ mean and basal testosterone concentrations during BL11 than during BL4/5 and BL7 (Table 4).

\section{Pulse characteristics and distribution}

The frequency and amplitude of $\mathrm{LH}$ pulses in the control bulls were higher $(P<0.05)$ during BL4/5 than during BL11 (Table 2). During BL4/5, all the controls $(12 / 12)$ had detectable LH pulses which were of greater $(P<0.05)$ frequency, amplitude and duration than the LH pulses that occurred in the medium (6/12) and high (3/12) antibody titre bulls that had pulses (Table 2). The amplitude of the LH pulses was higher $(P<0.05)$ in the controls compared with the high antibody titre bulls during BL7 and BL11, but LH pulse amplitude was higher $(P<0.05)$ in the controls compared with the medium antibody titre group during BL4/5 only (Table 2).

All of the control bulls (6/6) had FSH episodic secretions of higher $(P<0.05)$ frequency and amplitude during BL4/5 than those which occurred in the control bulls (3/6) during BL11 (Table 3). The amplitude and duration of the FSH episodic secretions were lower $(P<0.05)$ in the high antibody titre bulls compared with the controls during BL4/5 and BL7 (Table 3).

All of the control bulls $(6 / 6)$ had testosterone episodic secretions of higher $(P<0.05)$ frequency during BL7 than those which occurred in the control bulls during BL4/5 $(3 / 6)$ or BL11 $(4 / 6$; Table 4$)$. There were no detectable testosterone episodic secretions in the high antibody titre bulls $(0 / 6)$ during BL4/5 (Table 4). The frequency of testosterone episodic secretions was lower $(P<0.05)$ in both the medium $(3 / 6)$ and high $(3 / 6)$ antibody titre groups than in the controls $(6 / 6)$ during BL7 (Table 4). The amplitude of the testosterone episodic secretions was higher $(P<0.05)$ in the high antibody titre group $(6 / 6)$ than in the controls (4/6) during BL11 (Table 4). 
Table 2. The overall mean and basal LH concentrations, the proportion of animals per group with pulses and the mean frequency, amplitude and duration of LH pulses in plasma samples taken every $15 \mathrm{~min}$ for $8 \mathrm{~h}$ at $4-5$ months (BL4/5), 7 months (BL7) and 11 months of age (BL11) from bulls immunized at 8-10 weeks of age against a GnRH-human serum albumin

(HSA) conjugate or HSA

\begin{tabular}{|c|c|c|c|c|c|c|c|}
\hline \multirow[b]{2}{*}{ Bleed } & \multirow{2}{*}{$\begin{array}{l}\text { Antibody } \\
\text { titre group }\end{array}$} & \multirow{2}{*}{$\begin{array}{c}\text { Mean } \\
\left(\mathrm{ng} \mathrm{ml}^{-1}\right)\end{array}$} & \multirow{2}{*}{$\begin{array}{c}\text { Basal } \\
\left(\mathrm{ng} \mathrm{ml^{-1 }}\right)\end{array}$} & \multirow{2}{*}{$\begin{array}{l}\text { Proportion of bulls } \\
\text { with pulses }\end{array}$} & \multicolumn{3}{|c|}{ Pulse characteristics } \\
\hline & & & & & Frequency per $8 \mathrm{~h}$ & Amplitude $\left(\mathrm{ng} \mathrm{ml}^{-1}\right)^{*}$ & Duration $(\mathrm{min})^{*}$ \\
\hline \multirow[t]{3}{*}{ BL4/5 } & Control & $2.9^{\mathrm{ad}}$ & $1.8^{\text {ad }}$ & $12 / 12$ & $5.2^{\text {ad }}$ & $3.8^{\text {ad }}$ & $57.5^{\mathrm{a}}$ \\
\hline & Medium & $1.2^{\mathrm{bd}}$ & $1.1^{\mathrm{bd}}$ & $6 / 12$ & $1.5^{\mathrm{b}}$ & $1.5^{\mathrm{b}}$ & $37.5^{b}$ \\
\hline & High & $0.9^{\text {bd }}$ & $0.8^{\text {bd }}$ & $3 / 12$ & $0.5^{b}$ & $1.1^{b}$ & $35.0^{\text {bde }}$ \\
\hline \multirow[t]{3}{*}{ BL7 } & Control & $1.3^{\mathrm{e}}$ & $1.0^{\mathrm{c}}$ & $12 / 12$ & $2.4^{\mathrm{e}}$ & $2.4^{\text {ae }}$ & $50.8^{3}$ \\
\hline & Medium & $1.1^{\mathrm{d}}$ & $1.0^{\mathrm{d}}$ & $7 / 12$ & 1.3 & $1.7^{\mathrm{ab}}$ & $41.8^{\mathrm{a}}$ \\
\hline & High & $1.2^{\mathrm{d}}$ & $1.1^{\mathrm{d}}$ & $6 / 12$ & 1.3 & $1.0^{\mathrm{b}}$ & $22.0^{\mathrm{bd}}$ \\
\hline \multirow[t]{4}{*}{ BL11 } & Control & $1.9^{f}$ & $1.8^{\mathrm{d}}$ & $8 / 12$ & $1.2^{\mathrm{e}}$ & $2.3^{\text {ae }}$ & 56.4 \\
\hline & Medium & $2.0^{\mathrm{c}}$ & $1.9^{\mathrm{e}}$ & $5 / 12$ & 0.7 & $1.6^{\mathrm{ab}}$ & 46.5 \\
\hline & High & $1.9^{e}$ & $1.8^{\mathrm{e}}$ & $6 / 12$ & 1.0 & $1.2^{\mathrm{b}}$ & $53.4^{\circ}$ \\
\hline & $\mathrm{SED}^{+}$ & 0.27 & 0.22 & & 0.66 & 0.53 & 9.76 \\
\hline
\end{tabular}

Bulls were immunized at 8-10 weeks of age against a GnRH-HSA conjugate or HSA, selected at 13-19 weeks of age based on GnRH antibody titres and allocated to one of three antibody titre groups: control ( $n=12 ; 0.3 \pm 0.1 \%$ binding at a $1: 160$ dilution), medium $(n=12 ; 32 \pm 2 \%$ binding) and high ( $n=12 ; 51 \pm 2 \%$ binding). stck Means within bleed and within a column with different superscripts are significantly different $(P<0.05$; two-sided test).

def Means within antibody titre group but across bleed (within a column) with different superscripts are significantly different $(P<0.05$; two-sided test).

*Mean only of animals with pulses; ${ }^{\dagger}$ treatment $x$ bleed SED.

Table 3. The overall mean and basal FSH concentrations, the proportion of animals per group with episodic secretions and the mean frequency, amplitude and duration of FSH episodic secretions in plasma samples taken every 15 min for $8 \mathrm{~h}$ at $4-5$ months (BL4/5), 7 months (BL7) and 11 months of age (BL11) from bulls immunized at 8-10 weeks of age against a GnRH-human serum albumin (HSA) conjugate or HSA

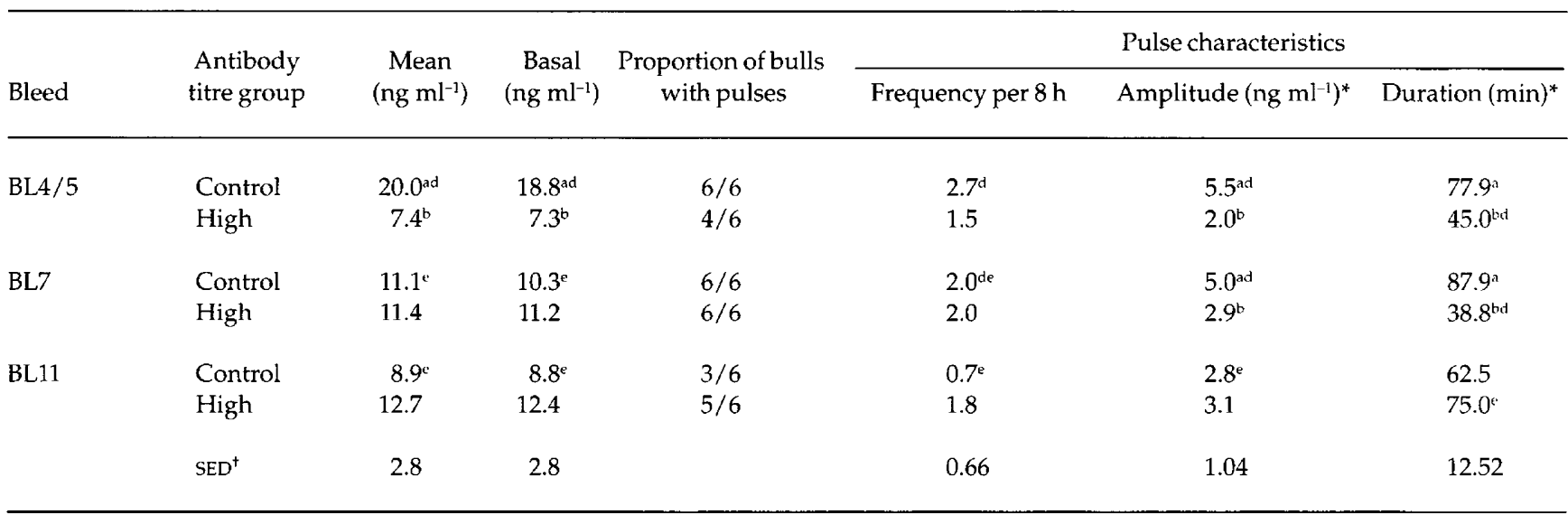

Bulls were immunized at 8-10 weeks of age against a GnRH-HSA conjugate or HSA, selected at 13-19 weeks of age based on GnRH antibody titres and allocated to one of two antibody titre groups: control ( $n=6 ; 0.3 \pm 0.1 \%$ binding at a $1: 160$ dilution) and high $(n=6 ; 51 \pm 2 \%$ binding).

ab Means within bleed and within a column with different superscripts are significantly different $(P<0.05$; two-sided test).

'Means within antibody titre group but across bleed (within a column) with different superscripts are significantly different $(P<0.05$; two-sided test).

*Mean only of animals with episodic secretions; ${ }^{+}$treatment $\times$bleed SED.

\section{Temporal relationships}

The hormone profiles and detected LH pulses and FSH and testosterone episodic secretions for one representative animal from each of the control and high antibody titre groups are presented in Figs 1 and 2, respectively. There was a decrease in the proportion of LH pulses followed within
75 min by FSH episodic secretions from $62.5 \%$ at BL $4 / 5$ to $0 \%$ at BL11 in the controls (Table 5). There were no LH pulses and therefore no temporal relationships between hormones in the high antibody titre bulls during BL4/5 (Table 5). GnRH immunization had no effect $(P>0.05)$ on the temporal relationship between LH and FSH during BL7; however, this temporal relationship was greater $(P<0.05)$ in the high 
Table 4. The overall mean and basal testosterone concentrations, the proportion of animals per group with episodic secretions and the mean frequency, amplitude and duration of testosterone episodic secretions in plasma samples taken every 15 min for $8 \mathrm{~h}$ at $4-5$ months (BL4/5), 7 months (BL7) and 11 months of age (BL11) from bulls immunized at 8-10 weeks of age against a

GnRH-human serum albumin (HSA) conjugate or HSA

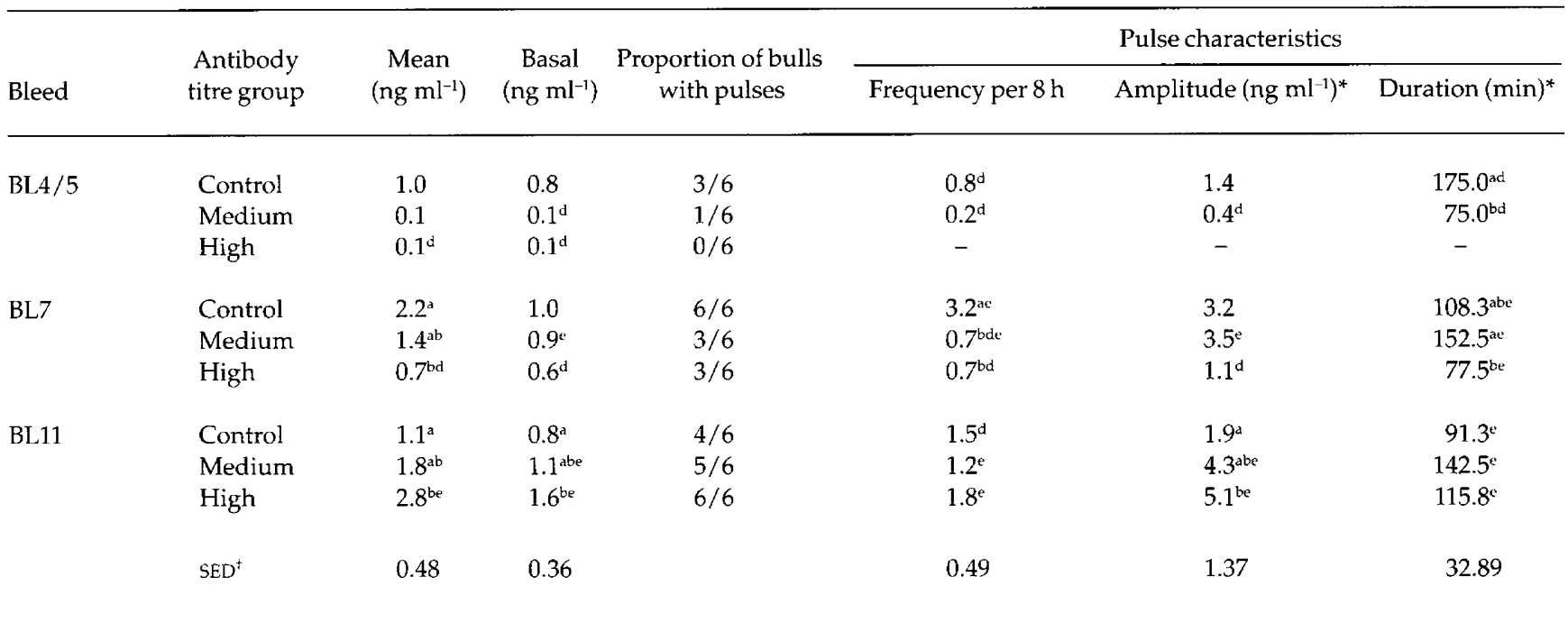

Bulls were immunized at 8-10 weeks of age against a GnRH-HSA conjugate or HSA, selected at 13-19 weeks of age based on GnRH antibody titres and allocated to one of three antibody titre groups: control $(n=6 ; 0.3 \pm 0.1 \%$ binding at a $1: 160$ dilution), medium $(n=6 ; 32 \pm 2 \%$ binding) and high $(n=6 ; 51 \pm 2 \%$ binding).

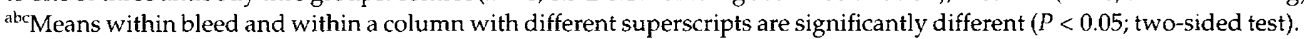

defMeans within antibody titre group but across bleed (within a column) with different superscripts are significantly different ( $P<0.05$; two-sided test).

*Mean only of animals with pulses; ttreatment $x$ bleed SED.

antibody titre bulls compared with the control bulls during BL11 (Table 5). The temporal relationship between LH and testosterone was greater $(P<0.05)$ in the controls compared with the high antibody titre group during BL7; however, there was no effect $(P>0.05)$ of GnRH immunization on this temporal relationship during BL11 (Table 5).

\section{Discussion}

This study demonstrates the following in bulls: (i) there is a definite episodic secretory pattern of release for $\mathrm{LH}, \mathrm{FSH}$ and testosterone and changes occur in these secretory patterns during the first year of life; (ii) there is a temporal relationship between $\mathrm{LH}$ and FSH at the pre- and peripubertal phases of development but not after puberty; and (iii) the closest temporal relationship between $\mathrm{LH}$ and testosterone occurs during the peripubertal phase of development. With respect to GnRH immunization this study demonstrates: (i) GnRH antibody titres of the order of $30-50 \%$ binding at a $1: 160$ plasma dilution in 3-5-month-old bulls cause almost complete inhibition of the pulsatile release of $\mathrm{LH}$ and the episodic release of FSH and testosterone up to 7 months of age; and (ii) a difference in GnRH antibody titres in 3-4-month-old bulls of the order of $20 \%$ binding at a $1: 160$ dilution does not have an effect on the parameters measured.

In agreement with previous findings, this study showed that mean LH concentrations decreased after 4-5 months of age and a decrease in mean FSH concentrations occurred around 7 months of age (MacMillan and Hafs, 1968; Evans et al., 1993). However, McCarthy et al. (1979b) and Schanbacher (1979) reported no changes in mean FSH concentrations in bulls from 1 to 10 or 1 to 12 months of age, respectively. These contrasting results may be due to the low frequency of blood sampling used in the cited references (three samples and one sample per month, respectively).

In the present study no age-related change was detected in the mean concentrations of testosterone in the control bulls. In addition, some of the controls had no testosterone episodic secretions during BL11. In another part of our research with these bulls (Finnerty et al., 1996), in which testosterone concentrations were measured every 2 weeks from 3 to 20 months of age, mean testosterone concentrations were noted to increase rapidly to $3 \mathrm{ng} \mathrm{ml}^{-1}$ from 4 to 5 months of age and to oscillate between 1.5 and $3 \mathrm{ng} \mathrm{ml}^{-1}$ from approximately 6 to 22 months of age. Similarly, in a study by Secchiari et al. (1976), testosterone concentrations in Friesian bulls were reported to rise gradually between 4 and 5.5 months of age, but, from 6.5 months of age, concentrations oscillated between 2 and $4 \mathrm{ng} \mathrm{ml}^{-1}$ at intervals of 2.5 months. There are several studies that report a sudden drop in testosterone concentrations in the bull from 8 to 12 months of age (Swanson et al., 1971; Rawlings et al., 1972; Sundby and Velle, 1980). Furthermore, Foote et al. (1976) and Stumpf et al. (1993) reported lower plasma testosterone concentrations in the autumn than in the spring in bulls ranging in age from 8 months to 13.5 years. The lower testosterone concentrations detected during BL11 (autumn) in the present study may be due to a normal oscillatory trend in testosterone concentrations in the bull or to a seasonal effect.

Similar to the findings of previous studies (McCarthy et al., 
$\mathrm{BL} 4 / 5$

(a)

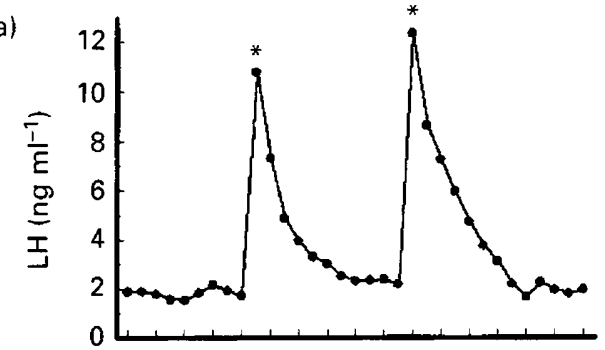

(b)

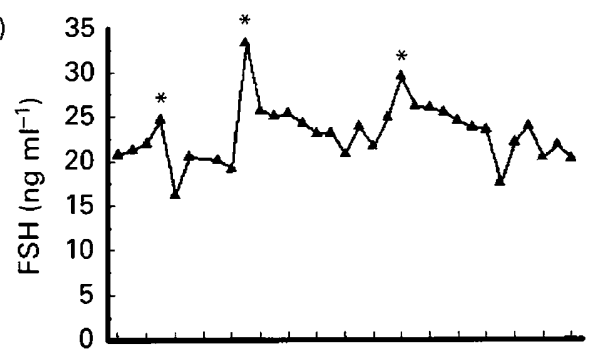

(c)

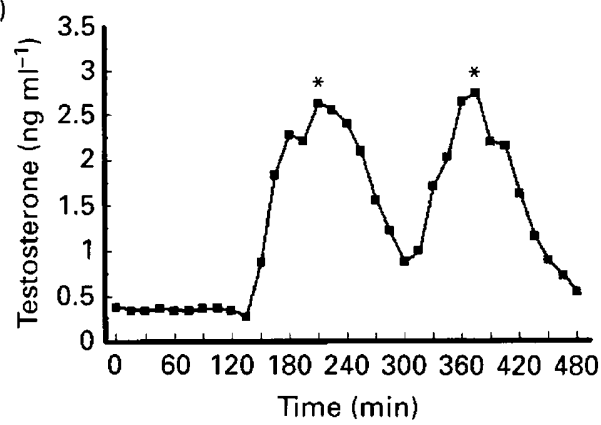

$B L 7$
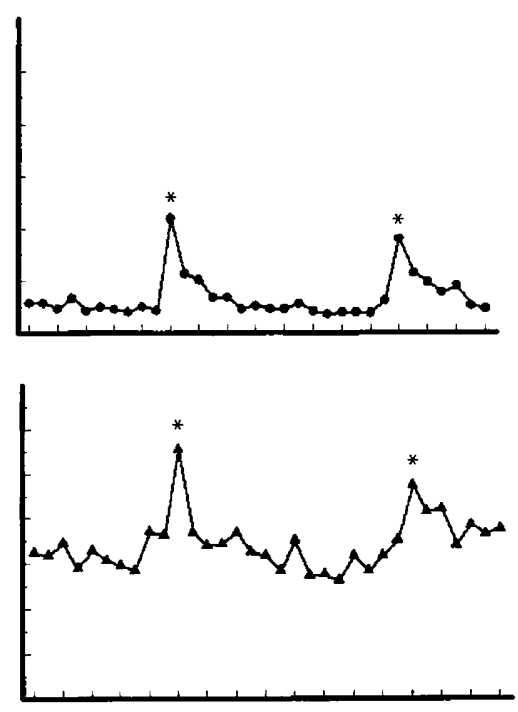

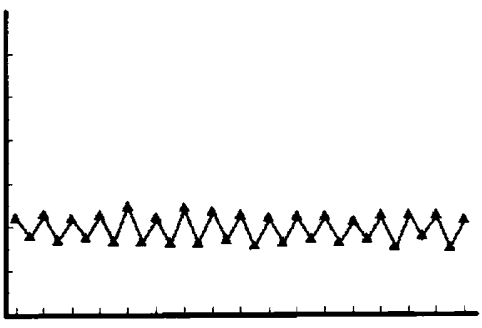

$\mathrm{BL} 11$
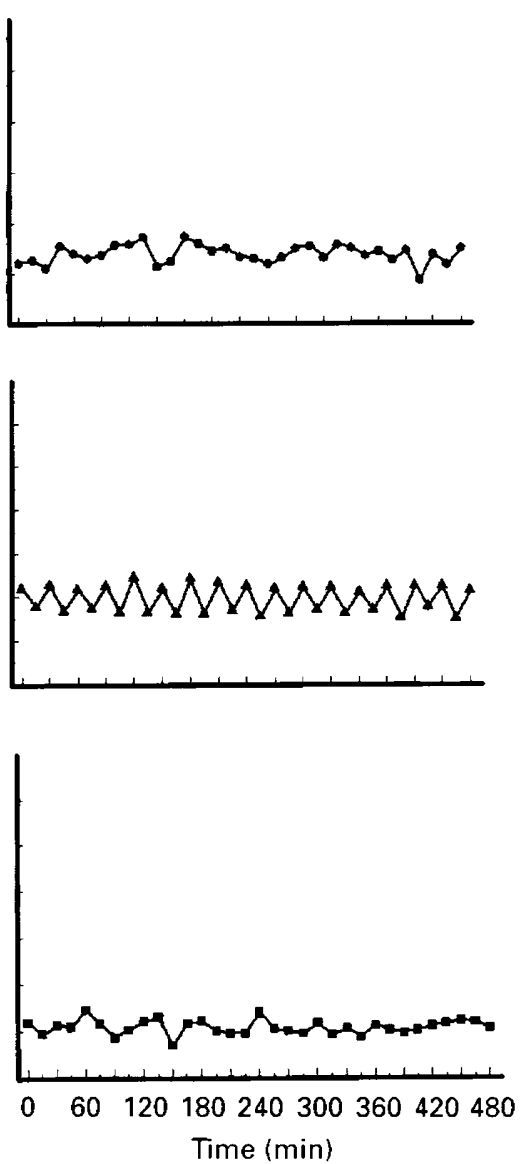

Fig. 1. Plasma (a) LH, (b) FSH and (c) testosterone concentrations in blood samples taken from an individual representative of a group of bulls immunized at 8-10 weeks of age against human serum albumin. Blood samples were taken every 15 min for $8 \mathrm{~h}$ at $4-5$ months (BL4/5), 7 months (BL7) and 11 months of age (BL11). ${ }^{*}$ The peak of pulses as identified by the PULSAR pulse detection program of Merriam and Wachter (1982).

1979a,b) the highest frequency and amplitude of LH pulses occurred at 4-5 months of age and the highest frequency of testosterone episodic secretions occurred at 7 months of age in the control bulls. The closest temporal relationship between testosterone and LH appeared to occur at 7 months of age; however, there was still a close temporal relationship at 11 months of age. Similarly, Rawlings et al. (1978) noted that plasma LH concentrations were more closely related to plasma testosterone concentrations from approximately 9 to 11 months of age than at any other age.

The highest frequency of FSH episodic secretions occurred in the control bulls during BL4/5. However, very few FSH episodic secretions were detected during BL11; this appeared to be due to the rapidly oscillating pattern of release of FSH at this stage. Lincoln (1978) found that pulses of plasma LH were associated with increases in both FSH and testosterone concentrations in rams with rapidly growing testes. Similarly, in the present study there was a close temporal relationship between $\mathrm{LH}$ and FSH in the control bulls during periods of rapid reproductive development (that is, $4 / 5$ and 7 months of age), but this relationship disappeared after the bulls reached puberty. In contrast, Schams et al. (1978) reported a very clear relationship between testosterone episodic secretions and LH pulses and between FSH episodic secretions and LH pulses in two 11-month-old Friesian bulls.

In the present study there was a higher mean concentration of $\mathrm{LH}$ and FSH and a greater temporal relationship between LH and FSH at 4-5 months of age than at 11 months of age. It has been demonstrated that a high concentration of FSH is required in the prepubertal bull in order to initiate spermatogenesis (Courot, 1967). In addition, MacMillan and Hafs (1968) demonstrated that total pituitary FSH content was greatest at 6 months of age in the bull, a time of intensive reproductive development. The lack of a temporal relationship between $\mathrm{LH}$ and FSH in the post-pubertal bull in the present study demonstrates that fluctuations in FSH concentrations occur independently of LH at this stage. These data provide further evidence for the differential control of LH and FSH release in the older male and their common control before puberty. Miyamoto et al. (1989) demonstrated that an increased production of inhibin occurs in the bull testis after 7 months of age which may be responsible at a later stage for the differential control of FSH secretion. Furthermore, it has been shown that increases in testosterone concentrations may have a negative feedback effect on the release of FSH in the older bull (Amann and Schanbacher, 1983; Schanbacher and Echternkamp, 1978). 
(a)

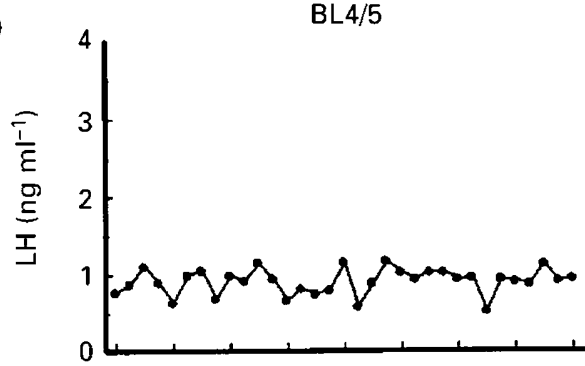

(b)

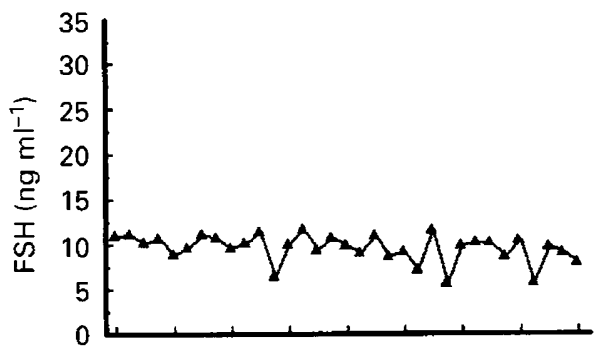

(c)

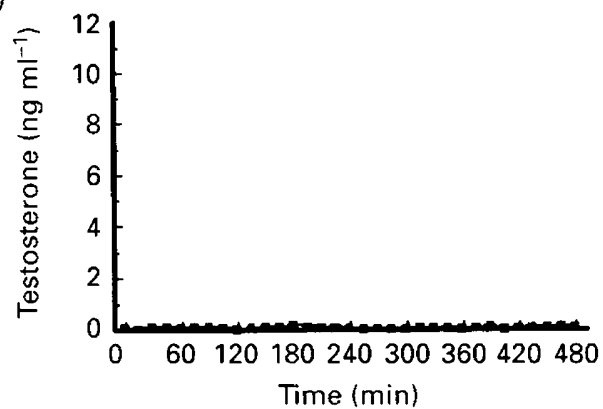

BL7
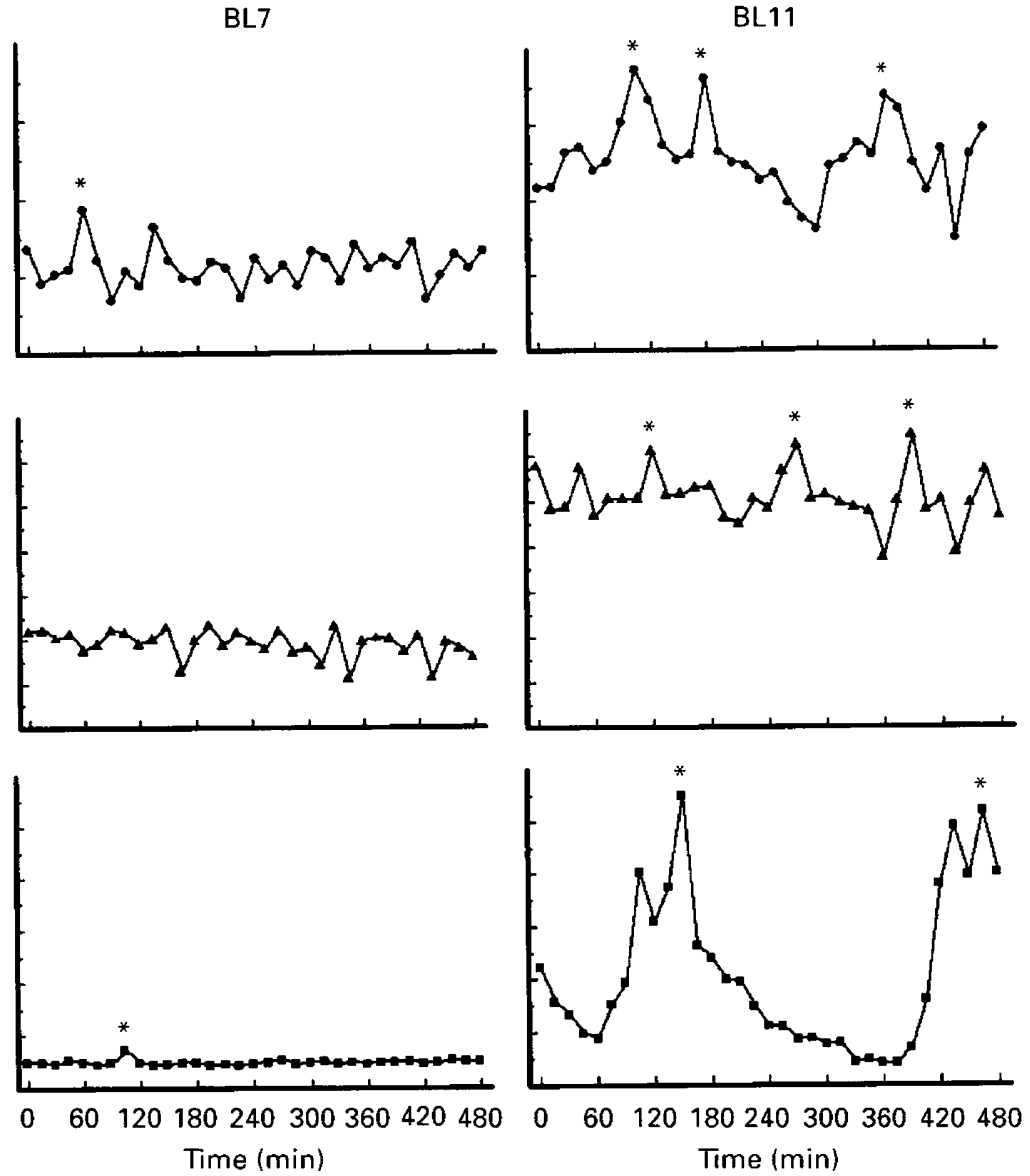

Fig. 2. Plasma (a) LH, (b) FSH and (c) testosterone concentrations in blood samples taken from an individual representative of a group of bulls immunized at 8-10 weeks of age against a GnRH-human serum albumin conjugate, and allocated at 13-19 weeks of age to a high GnRH antibody titre group $(n=6 ; 51 \pm 2 \%$ binding at a 1:160 plasma dilution). Blood samples were taken every $15 \mathrm{~min}$ for $8 \mathrm{~h}$ at $4-5$ months (BL4/5), 7 months (BL7) and 11 months of age (BL11). ${ }^{*}$ The peak of pulses as identified by the PULSAR ${ }^{*}$ pulse detection program of Merriam and Wachter (1982)

During BL4/5, both of the GnRH-immunized groups had lower mean LH and FSH concentrations than the controls, which were due to lower frequencies, amplitudes and durations of pulses or episodic secretions of both hormones. The fact that GnRH immunization suppressed both LH and FSH secretion at this prepubertal stage suggests that GnRH is an important common factor controlling the release of both these hormones at this stage. However, despite the continued presence of significant titres, the biological effect of $\mathrm{GnRH}$ immunization on hormone parameters decreased over time. Another study with these GnRH-immunized animals showed that they experienced a delayed pubertaltype rise in testosterone concentrations at approximately 7 months of age (Finnerty et al., 1996). This increase in testosterone occurred even in the absence of the normal agerelated increase in LH pulse frequency and amplitude and in the presence of significant GnRH antibody titres. The tonic release of LH up to 7 months of age may have been sufficient to cause this delayed pubertal-type increase in testosterone at this stage of development. Previously, prepubertal bulls receiving GnRH agonists showed increased testosterone concentrations even in the absence of LH pulses (Melson $e t$ al., 1986; Ronayne et al., 1993).
The initial significant difference in antibody titres between the medium and high antibody titre groups did not have a great effect on the hormone variables measured. However, the high antibody titre group had numerically lower mean and basal LH concentrations and lower mean values for other variables measured during BL4/5 compared with the medium antibody titre group. The amplitude and duration of LH pulses and FSH episodic secretions were still significantly less in the high antibody titre bulls than in the controls at BL7, whereas the medium antibody titre bulls were different from the controls during BL4/5 only. These observations suggest that, the higher the GnRH antibody titre before puberty, the greater the duration of its biological effects.

In conclusion, these data demonstrate a close temporal relationship between the pattern of release of $\mathrm{LH}$ and FSH, and $\mathrm{LH}$ and testosterone, and that these relationships change during the development of the bull in the first year of life. Data from the GnRH-immunized bulls provide evidence for the common control of both LH and FSH release by GnRH before puberty and for the presence of other factors that control the release of FSH in the older bull. In addition, these results suggest that long-term tonic release of LH may be 
Table 5. The total number of LH pulses that occurred during the first $6.5 \mathrm{~h}$ of an $8 \mathrm{~h}$ bleed and the percentage (number) of these LH pulses that were followed within 75 min by episodic secretions of FSH and testosterone in blood samples taken every $15 \mathrm{~min}$ for $8 \mathrm{~h}$ at 4-5 months (BL4/5), 7 months (BL7) and 11 months of age (BL11) from bulls immunized at 8-10 weeks of age against a GnRH-human serum albumin (HSA) conjugate or HSA

\begin{tabular}{|c|c|c|c|c|}
\hline \multirow[b]{2}{*}{ Bleed } & \multirow[b]{2}{*}{ Antibody titre group } & \multirow[b]{2}{*}{ Total number of LH pulses } & \multicolumn{2}{|c|}{ Percentage (number) of $\mathrm{LH}$ pulses followed by: } \\
\hline & & & FSH & Testosterone \\
\hline \multirow[t]{2}{*}{$\mathrm{BL} 4 / 5$} & Control & 24 & $62.5(15)$ & $16.0(4)$ \\
\hline & High & 0 & - & - \\
\hline \multirow[t]{2}{*}{ BL7 } & Control & 15 & $53.3(8)$ & $86.7(13)^{\mathrm{a}}$ \\
\hline & High & 8 & $50.0(4)$ & $12.5(1)^{\mathrm{b}}$ \\
\hline \multirow[t]{2}{*}{ BL11 } & Control & 8 & $0.0(0)^{\mathrm{a}}$ & $50.0(4)$ \\
\hline & High & 7 & $71.4(5)^{b}$ & $57.1(4)$ \\
\hline
\end{tabular}

Bulls were immunized at 8-10 weeks of age against a $\mathrm{GnRH}-\mathrm{HSA}$ conjugate or HSA, selected at 13-19 weeks of age based on GnRH antibody titres and allocated to two antibody titre groups: control $(n=6 ; 0.3 \pm 0.1 \%$ binding at a $1: 160$ dilution) and high ( $n=6$; $51 \pm 2 \%$ binding)

ab Means within bleed and within a column with different superscripts are significantly different $(P<0.05$; two-sided test).

sufficient to initiate a late pubertal-type increase in testosterone concentrations.

The authors thank the staff at Teagasc, Grange Research Centre, for assistance with animal handling and blood sampling, K. Bannon (Grange Research Centre, deceased) and D. Prendiville for expert technical assistance, N. Hynes in the Animal Husbandry Department of the Faculty of Veterinary Medicine (University College Dublin) for her assistance with the FSH assay, the staff and students in the Animal Husbandry and Production Department of the Faculty of Veterinary Medicine (University College Dublin) for their assistance during intensive blood sampling periods, T. Hegarty and B. Gleeson (Teagasc) for assistance with statistical analyses, M. Smith for typing the manuscript, and A. F. Parlow (National Institute of Diabetes and Digestive Kidney Diseases) for the kind donation of LH antiserum and standard. M. Finnerty was a recipient of a Teagasc University postgraduate research grant and also received financial assistance from BioResearch Ireland during the course of this study.

\section{References}

Amann RP and Schanbacher BD (1983) Physiology of male reproduction Journal of Animal Science 57 Supplement 2380-403

Brown BW, Mattner PE, Carroll PA, Holland EJ, Paull DR, Hoskinson RM and Rigby RDG (1994) Immunization of sheep against GnRH early in life: effects on reproductive function and hormones in rams fournal of Reproduction and Fertility 101 15-21

Courot M (1967) Endocrine control of the supporting and germ cells of the impubertal testis Journal of Reproduction and Fertility Supplement 2 89-101

Courot M (1978) Prepubertal development and puberty: comparative aspects International Journal of Andrology Supplement 1 11-20

Crowe MA, Padmanabhan V, Hynes N, Sunderland SJ, Enright WJ, Beitins IZ and Roche JF (1997) Validation of a sensitive radioimmunoassay to measure serum follicle stimulating hormone in cattle: correlation with biological activity Animal Reproduction Science 48 123-136

D'Occhio MI, Gifford DR, Weatherly T and Setchell BP (1986) Evidence of gonadal steroid-independent changes in activity of the central LH-releasing hormone pulse generator in developing bull calves Journal of Endocrinology 111 67-73

Ellis GB and Desjardins C (1982) Male rats secrete luteinizing hormone and testosterone episodically Endocrinology 110 1618-1627
Evans ACO, Currie WD and Rawlings NC (1993) Opioidergic regulation of gonadotrophin secretion in the early prepubertal bull calf Journal of Reproduction and Fertility 99 45-51

Finnerty M, Enright WJ, Morrison CA and Roche JF (1994) Immunization of bull calves with a gonadotrophin-releasing hormone-human serum albumin conjugate: effect of conjugate dose, type of adjuvant and booster interval on immune, endocrine, testicular and growth responses Journal of Reproduction and Fertility $101333-343$

Finnerty M, Enright WJ, Prendiville DJ, Spicer LJ and Roche JF (1996) The effect of different levels of anti-gonadotrophin releasing hormone ( $\mathrm{GnRH}$ ) antibody titres on plasma hormone concentrations, sexual and aggressive behaviour, testes size and performance of bulls Animal Science 63 51-63

Foote RH, Munkenbeck N and Green WA (1976) Testosterone and libido in Holstein bulls of various ages Journal of Dairy Science 59 2011-2013

Gill JJ (1978) Design and Analysis of Experintents in the Animal and Medical Sciences Vol. 2 Iowa State University Press, Ames

Karg H, Gimenez T, Hartl M, Hoffmann B, Schallenberger E and Schams D (1976) Testosterone, luteinizing hormone (LH) and follicle stimulating hormone (FSH) in peripheral plasma of bulls: levels from birth through puberty and short-term variations Zentralblatt fur Veterinarmedizin $23 \mathrm{~A}$ 793-803

Katongole CB, Naftolin F and Short RV (1971) Relationships between blood levels of luteinizing hormone and testosterone in bulls, and the effects of sexual stimulation Journal of Endocrinology 50 457-466

Lee VWK, Cumming IA, de Kretser DM, Findlay JK, Hudson B and Keogh EF (1976) Regulation of gonadotropin secretion in rams from birth to sexual maturity I. Plasma LH, FSH and testosterone levels Journal of Reproduction and Fertility $461-6$

Lincoln GA (1976) Seasonal variation in the episodic secretion of luteinizing hormone and testosterone in the ram Journal of Endocrinology 69 213-216

Lincoln GA (1978) The temporal relationship between plasma levels of FSH and LH in the ram Journal of Reproduction and Fertility 53 31-37

Lincoln GA and Fraser HM (1979) Blockage of episodic secretion of luteinizing hormone in the ram by the administration of antibodies to luteinizing hormone releasing hormone Biology of Reproduction 21 1239-1245

Lunstra DD, Ford JJ and Echternkamp SE (1978) Puberty in beef bulls: hormone concentrations, growth, testicular development, sperm production and sexual aggressiveness in bulls of different breeds journal of Animal Science 46 1054-1062

McCarthy NS, Convey EM and Hafs HD (1979a) Serum hormonal changes and testicular response to LH during puberty in bulls Biology of Reproduction $201221-1227$

McCarthy NS, Hafs HD and Convey EM (1979b) Serum hormone patterns associated with growth and sexual development in bulls Journal of Animal Science 49 1012-1020 
MacMillan KL and Hafs HD (1968) Pituitary and hypothalamic endocrine changes associated with reproductive development of Holstein bulls Journal of Animal Science 27 1614-1620

Malak GA and Thibier M (1985a) Lack of relationship between spontaneous fluctuations of FSH, LH and testosterone and semen quality in young postpubertal buils Zuchthy $20222-228$

Malak GA and Thibier M (1985b) Individual variations in FSH release after a GnRH challenge and relationship with semen output in young bulls Journal of Reproduction and Fertility 75 345-350

Melson BE, Brown JL, Schoenemann HM, Tarnavsky GK and Reeves JJ (1986) Elevation of serum testosterone during chronic LHRH agonist treatment in the bull Journal of Animal Science 62 199-207

Merriam GR and Wachter KW (1982) Algorithms for the study of episodic hormone secretion American Journal of Physiology 243 E310-E318

Miyamoto A, Umezu M, Ishii S, Furusawa T, Masaki J, Hasegawa $Y$ and Ohta M (1989) Serum inhibin, FSH, LH and testosterone levels and testicular inhibin content in beef bulls from birth to puberty Animal Reproduction Science 20 165-178

Rawlings NC, Hafs HD and Swanson LV (1972) Testicular and blood plasma androgens in Holstein bulls from birth through puberty journal of Animal Science 34 435-440

Rawlings NC, Fletcher PW, Henricks DM and Hill JR (1978) Plasma luteinizing hormone $(\mathrm{LH})$ and testosterone levels during sexual maturation in beef bull calves Biology of Reproduction 19 1108-1112

Rodriguez RE and Wise ME (1989) Ontogeny of pulsatile secretion of gonadotropin-releasing hormone in the bull calf during infantile and pubertal development Endocrinology 124 248-256

Ronayne E, Enright WJ and Roche JF (1993) Effects of continuous administration of gonadotrophin-releasing hormone (GnRH) or a potent $\mathrm{GnRH}$ analogue on blood luteinizing hormone and testosterone concentrations in prepubertal bulls Domestic Animal Endocrinology $\mathbf{1 0}$ 179-189

Schams D, Gombe S, Schallenberger E, Reinhardt V and Claus R (1978) Relationships between short-term variations of $\mathrm{LH}, \mathrm{FSH}$ and prolactin and testosterone in peripheral plasma of prepubertal bulls lournal of Reproduction and Fertility 54 145-148

Schanbacher BD (1979) Relationship of in vitro gonadotropin binding to bovine testes and the onset of spermatogenesis Journal of Animal Science $\mathbf{4 8}$ 591-597

Schanbacher BD (1982) Responses of ram lambs to active immunization against testosterone and luteinizing hormone releasing hormone American Journal of Physiology 242 E201-E205

Schanbacher BD and Echternkamp SE (1978) Testicular steroid secretion in response to GnRH-mediated LH and FSH release in bulls Journal of Animal Science 46 514-520

Secchiari P, Martorana F, Pellegrini S and Luisi M (1976) Variation of plasma testosterone in developing Friesian bulls journal of Animal Science 42 405-409

Siegel S (1956) In Nonparametric Statistics for the Behavioral Sciences Ed. HF Harlow. McGraw-Hill, New York

Stumpf TT, Wolfe MW, Robertson MS, Kittok RJ and Kinder JE (1993) Season of the year influences concentration and pattern of gonadotropins and testosterone in circulation of the bovine male Biology of Reproduction 49 1089-1095

Sundby A and Velle W (1980) Plasma concentrations of testosterone in young bulls in relation to age, rate of mass gain and stimulation with human chorionic gonadotrophin Journal of Endocrinology 86 465-469

Swanson LV, Wettemann RP, Rawlings NC, Hafs HD and Magee WT (1971) Pubertal relationships of some endocrine and reproductive criteria in Hereford bulls Journal of Animal Science 33 823-828 